0013-4651/2004/152(1)/A37/5/\$7.00 @ The Electrochemical Society, Inc.

\title{
An Ellipsometric Study of Manganese Oxide Films
}

\section{In Situ Characterization of the Deposition and Electroreduction of $\mathrm{MnO}_{2}$}

\author{
M. Hernández Ubeda, ${ }^{a}$ M. A. Pérez, ${ }^{\text {b }}$ H. T. Mishima, ${ }^{a}$ H. M. Villullas, ${ }^{\text {b,d }}$ \\ J. O. Zerbino, ${ }^{c}$ B. A. López de Mishima, ${ }^{a}$ and M. López Teijelo ${ }^{b, *, z}$
}

${ }^{a}$ Instituto de Ciencias Químicas, Facultad de Agronomía y Agroindustrias,

Universidad Nacional de Santiago del Estero, 4200 Santiago del Estero, Argentina

'INFIOC, Departamento de Fisicoquímica, Facultad de Ciencias Químicas,

Universidad Nacional de Córdoba, 5000 Córdoba, Argentina

'INIFTA, 1900 La Plata, Argentina

The electrodeposition of manganese oxide films onto a platinum substrate was investigated by means of in situ ellipsometry. In the thickness range from 0 to $150 \mathrm{~nm}$, the anodic oxide behaves as an isotropic single layer with optical constants that are independent of thickness. Deviations at higher thickness are explained in terms of anisotropic properties of the film. The electroreduction of thin films (up to $c a .150 \mathrm{~nm}$ ) in an alkaline electrolyte leads to a decrease in both the refractive index and the extinction coefficient and is accompanied by a thickness increase of $c a .10 \%$. The $\mathrm{Mn}(\mathrm{IV})$ to $\mathrm{Mn}(\mathrm{III})$ conversion takes place from the oxide/electrolyte interface inwards.

(C) 2004 The Electrochemical Society. [DOI: 10.1149/1.1825951] All rights reserved.

Manuscript submitted January 28, 2004; revised manuscript received June 9, 2004. Available electronically November 17, 2004

The wide spread use of $\mathrm{MnO}_{2}$ for battery electrodes has continued over the years and has been extended today to nonaqueous lithium cells. ${ }^{1-4}$ Manganese dioxide can exist as various polytypes denoted $\alpha-, \beta-, \gamma$-, ramsdellite, $\delta$ - and $\lambda$-forms, with the $\gamma$-form, referred to as nsutite, being the most active electrochemically. Among the samples referred to as $\gamma-\mathrm{MnO}_{2}$ and depending on their origin, natural $\mathrm{MnO}_{2}$, chemical $\mathrm{MnO}_{2}$ (CMD), and electrolytic $\mathrm{MnO}_{2}$ (EMD) can be distinguished. The differences are associated to subtle structural changes. Electrolytic $\mathrm{MnO}_{2}$ films have been prepared using galvanostatic and potentiostatic methods. ${ }^{5,6}$ Amorphous hydrous manganese oxides anodically deposited from $\mathrm{MnSO}_{4}$ solutions of different $\mathrm{pH}$ show an acceptable capacity, high reversibility, and high pulse-power properties for electrochemical supercapacitors. $^{7,8}$

For battery-active manganese dioxides used in primary cells $(\gamma$ and $\left.\varepsilon-\mathrm{MnO}_{2}\right),{ }^{9}$ the electroreduction process during the first cycle in alkaline electrolytes has been extensively studied. Kozawa and coworkers observed that the reduction process depends on $\mathrm{KOH}$ concentration. ${ }^{9,10}$ Amarilla et al. ${ }^{11}$ have studied the influence of $\mathrm{KOH}$ concentration on the $\mathrm{MnO}_{2}$ redox mechanism using step potential electrochemical spectroscopy (SPECS) and X-ray diffraction (XRDS). In $1 \mathrm{M} \mathrm{KOH}$ the voltamperometric and XRD data show that the redox mechanism can be described as a $\mathrm{H}^{+} / \mathrm{e}^{-}$insertion/ desinsertion process with good reversibility. For strongly alkaline $\mathrm{KOH}$ solutions, a different redox mechanism is observed after the first cycle and a loss of electrochemical activity is also noticed.

In general, the reduction of $\gamma-\mathrm{MnO}_{2}$ occurs in two potential regions. The first step corresponds to a homogeneous reduction while the second step is a heterogeneous reduction process. Swinkels et al. ${ }^{12-14}$ investigated the reduction of electrodeposited manganese dioxide (EMD), birnessite, and Bi-birnessite electrodes and found that each type of manganese dioxide underwent a homogeneous reduction followed by a heterogeneous reduction stage.

The electrochemical process of insertion/desinsertion of $\mathrm{H}^{+}$was investigated by studying its influence on the evolution of the crystallographic structure of $\gamma-\mathrm{MnO}_{2}$ in EMD samples during the discharge and recharge processes of an alkaline battery using in situ $\mathrm{X}$-ray diffraction (XRD) ${ }^{15}$ During the first discharge, proton inser-

\footnotetext{
* Electrochemical Society Active Member.

${ }^{\mathrm{d}}$ Present address: Instituto de Química, UNESP, 14801-970, Araraquara, SP, Brazil

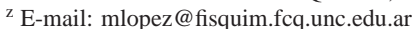

tion up to $0.4 \mathrm{H}^{+}$per $\mathrm{MnO}_{2}$ causes an expansion of the $\mathrm{MnO}_{2}$ crystalline cell. The lattice expansion is attributed to the reduction of $\mathrm{Mn}^{4+}$ to $\mathrm{Mn}^{3+}$.

The kinetic behavior and the semiconducting properties of manganese oxide films as well as the discharge processes were studied by electrochemical impedance spectroscopy (EIS). ${ }^{16}$ Manganese oxide films behave as n-type semiconductors. It was also found that the reduction is controlled by the diffusion of protons in the bulk oxide. The reduction and reoxidation process is reversible for thin layers while irreversibility was observed for thick films. The proton diffusion process was also studied in porous $\gamma-\mathrm{MnO}_{2} .{ }^{17}$ Other studies of the discharge process of electrodeposited manganese oxide have been reported. ${ }^{18-20}$ Raman spectroscopy, electrochemically modulated infrared reflectance spectroscopy (EMIRS), and X-ray photoemission spectroscopy (XPS) revealed that manganese oxide films are reduced to amorphous products, resulting in an oxidation number value not lower than three.

Only a few ellipsometric studies of manganese oxide have been published. The optical properties of films deposited by potentiostatic pulses were found to be strongly sensitive to the deposition conditions. ${ }^{21}$ The refractive index and the extinction coefficient were reported to be dependent of film thickness, which was attributed to the insular structure of the films and to surface roughening. The changes in extinction coefficient were attributed to changes in porosity. The electrodeposition reaction produced by galvanostatic pulses was also investigated. ${ }^{22}$ The extinction coefficient was found either to increase or to be independent of thickness in different thickness ranges. For relatively thick films optical data could not be interpreted in terms of uniform isotropic film models. ${ }^{21,22}$ The electroreduction of the manganese oxide films leads to a decreases of both the refractive index and the extinction coefficient. In addition, the reduction/oxidation processes were qualitatively studied during galvanostatic cycles.

More recently, the anodic growth of manganese oxide films prepared either by galvanostatic or potentiostatic pulses in the thickness range from 0 to $1000 \mathrm{~nm}$ was investigated by some of us. ${ }^{23,24}$ The results obtained can be reasonably fitted into the whole thickness range in terms of the uniaxial anisotropy of the films. The anisotropic properties were related to preferential orientation of the deposits. The optical response of cycled hydrous manganese oxide obtained by electro-oxidation of manganese hydroxide prepared through chemical precipitation, also showed that the films behave as anisotropic single layers, which is related to the morphology of the hydrous oxide layer. ${ }^{25}$ In this case, the electroreduction process also 
produces a decrease of the refractive indexes and a pronounced diminution of the extinction coefficients to yield an almost transparent film.

In the present paper, we report on an in situ ellipsometric investigation of the potentiostatic deposition of manganese oxide films and the change in optical properties obtained by electroreduction.

\section{Experimental}

The $\mathrm{MnO}_{2}$ films of different thicknesses were deposited onto a smooth platinum disk electrode from $0.1 \mathrm{M} \mathrm{MnSO}_{4}$ $+0.017 \mathrm{M} \mathrm{H}_{2} \mathrm{SO}_{4}$ solution ( $\mathrm{pH}$ 2) by applying potentiostatic pulses according to the procedure previously described. ${ }^{23}$ Pulses of $1 \mathrm{~s}(\Delta t=1 \mathrm{~s})$ were applied from an initial potential $E_{\text {in }}=0.65 \mathrm{~V}$ (vs. $\mathrm{Hg} / \mathrm{Hg}_{2} \mathrm{SO}_{4} / \mathrm{Na}_{2} \mathrm{SO}_{4} 1 \mathrm{M}$ ) to different final potential values $\left(E_{\mathrm{f}}\right)$, where the anodic deposition of $\mathrm{MnO}_{2}$ from $\mathrm{Mn}^{2+}$ takes place. ${ }^{23} E_{\mathrm{f}}$ was changed in the potential range from 0.68 to $0.90 \mathrm{~V}$. The number of pulses $(N)$ was varied between 2 and 100. The platinum substrate was cleaned in a $1: 1 \mathrm{H}_{2} \mathrm{SO}_{4}+\mathrm{HNO}_{3}$ mixture and then polished to a mirror surface with $0.05 \mu \mathrm{m}$ alumina. The electrolyte used for the electroreduction experiments was a $0.1 \mathrm{M}$ aqueous borate solution of $\mathrm{pH} 9.2$ prepared from Millipore water (MilliRo-MilliQ) and analytical grade reagents and was purged with purified nitrogen gas. Experiments were performed at $22^{\circ} \mathrm{C}$.

Ellipsometric data were obtained by using a three-compartment electrolysis cell made of Pyrex glass. The working electrode was mounted in a Teflon holder and placed horizontally in the cell compartment provided with two plane windows adequate for optical measurements. The electrolytic cell was mounted in a Rudolph Research rotating-analyzer automatic ellipsometer (vertical type, 2000 FT model) equipped with a $75 \mathrm{~W}$ tungsten lamp as the light source provided with a filter $(546.1 \mathrm{~nm})$. The signal of the photomultiplier was averaged twice, and data were collected in continuous mode during the experiments ( $c a .1 \mathrm{~s}$ between each point). The refractive index of the electrolyte was taken as 1.333. All measurements were performed at an angle of incidence of $70.00^{\circ}$. The $\Psi$ - $\Delta$ plots were analyzed according to different models. ${ }^{23,24}$ The Simplex Method $^{26,27}$ was used to minimize the error as previously described. $^{28,29}$

The anodic growth of manganese oxide films was followed ellipsometrically during the application of the potentiostatic pulses in the deposition solution. During the growth of thick films, the ellipticity angle, $\varepsilon$, (as defined in Ref. 30, p. 8) changes in sign $(-\pi / 4$ $\leqslant \varepsilon \leqslant \pi / 4$ ), in some cases several times during an entire experiment. In a rotating-analyzer ellipsometer, the sign of the ellipticity must be entered before starting the measurements, ${ }^{31}$ which are initiated with a negative value corresponding to the bare platinum substrate. As film thickness increases and ellipticity becomes positive (for $180^{\circ} \leqslant \Delta \leqslant 360^{\circ}$ in the $\Psi-\Delta$ plane), two options are possible. The first one is to maintain the negative sign in the instrument and perform the entire experiment. In this case, about a half of the $\Psi-\Delta$ data are not properly obtained, and they must be discarded. The second option is to stop the measurement as the region or change in sign is approached, change the sign accordingly, and then restart the measurement, repeating the procedure as many times as necessary. In both cases, and depending on the rate of film growth, some data are lacking.

In order to obtain the optical properties of the oxidized and electroreduced states, the following procedure was applied. After a given thickness of $\mathrm{MnO}_{2}$ was deposited, the electrode was carefully rinsed with purified water and placed in the borate solution; held at $+0.1 \mathrm{~V}$ for $3 \mathrm{~min}$, and then it was potentiodynamically electroreduced at $5 \mathrm{mV} \mathrm{s}^{-1}$ up to $-0.5 \mathrm{~V}$.

\section{Results and Discussion}

Anodic growth of the manganese oxide film.-The variation of the ellipsometric angles $\Psi$ and $\Delta$ recorded during a typical deposition experiment by applying potentiostatic pulses at $E_{\mathrm{f}}=0.68 \mathrm{~V}$ is shown in Fig. 1 (only the data with negative ellipticity are depicted).

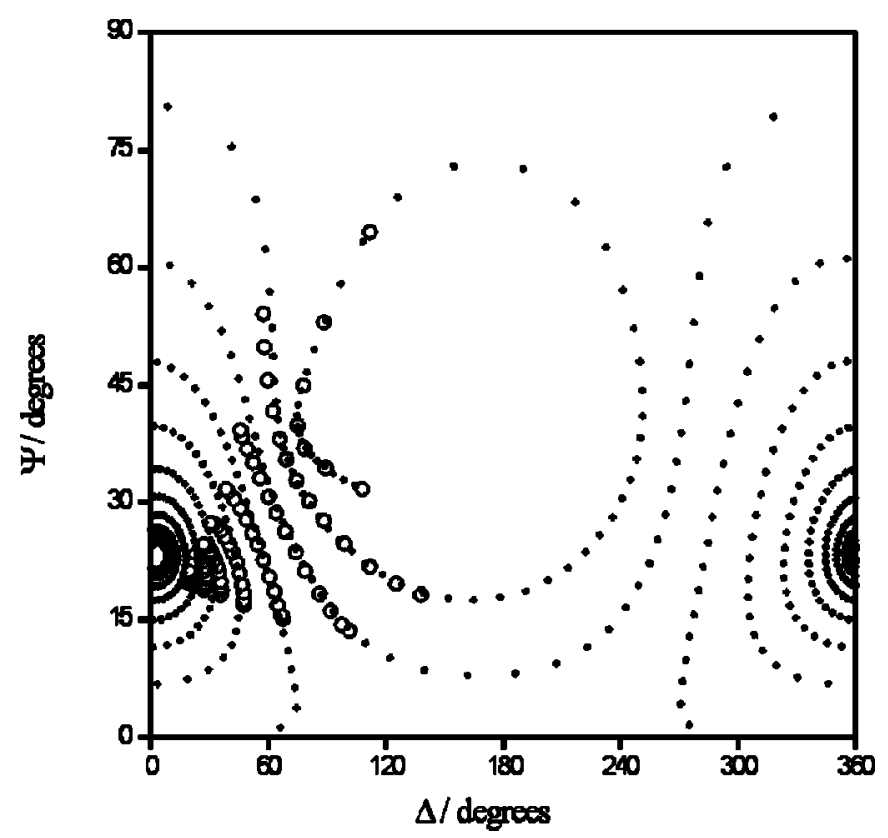

Figure 1. $\Psi-\Delta$ response obtained during $\mathrm{MnO}_{2}$ anodic growth by applying 100 potentiostatic pulses in a $0.1 \mathrm{M} \mathrm{MnSO}_{4}+0.017 \mathrm{M} \mathrm{H}_{2} \mathrm{SO}_{4}$ solution $(\mathrm{pH}$ 2). $E_{\text {in }}=0.65 \mathrm{~V}, E_{\mathrm{f}}=0.68 \mathrm{~V}$. (O) Experimental data; (O) theoretical curve for a single-layer model; $\left(\mathbf{n}_{\mathrm{f}}=1.858-0.060 i\right.$; thickness increments of $10 \mathrm{~nm}$ ).

Starting from the $\Psi$ and $\Delta$ values corresponding to the bare platinum substrate, the $\Psi-\Delta$ plot draws initially open loops and then it spirals inwards toward a different point as thickness increases. This $\Psi-\Delta$ response for the oxide growth is characteristic of a slightly absorbent film, and the point towards which it spirals at increasing thickness, is the point at which the film becomes the substrate as far as optical measurements are concerned. The results cannot be adequately fitted by means of a single-layer isotropic model ${ }^{30}$ in the whole range of thickness for a given value of the film complex refractive index $\left(\mathbf{n}_{\mathrm{f}}=n_{\mathrm{f}}-k_{\mathrm{f}} i\right.$, where $n_{\mathrm{f}}$ is the film refractive index and $k_{\mathrm{f}}$ is the film extinction coefficient). However, for thickness lower than $c a$. $150 \mathrm{~nm}$, the $\Psi-\Delta$ data can be adequately fitted by means of the single-layer model for a value of $\mathbf{n}_{\mathrm{f}}=1.858$ $-0.060 i$ (see Fig. 1). For thicknesses higher than $150 \mathrm{~nm}$ (successive loops), increasing deviations from the theoretical line corresponding to the single-layer model are observed. On the other hand, the point which the $\Psi-\Delta$ curve approaches high thickness values (the film behaves optically as if it were the substrate), leads to a value of $\mathbf{n}_{\mathrm{f}}=2.02-0.368 i$, i.e., a slight increase in $n_{\mathrm{f}}$ and a pronounced increase in $k_{\mathrm{f}}$ (from $k_{\mathrm{f}} \sim 0.06$ obtained from the best fit for thickness lower than $150 \mathrm{~nm}$, up to $k_{f} \sim 0.37$ when the film is very thick). Nevertheless, the simulated curve for $\mathbf{n}_{\mathrm{f}}=2.02$ - $0.368 i$ approaches the infinite thickness limit but does not fit the general behavior of the experimental results either in the thin film or in the thick film regions. On the contrary, the simulated curve with the parameters fitted for the low thickness regions describes qualitatively the shape of the curve in the thin film as well as in the thick film regions, although it spirals towards a different infinite thickness limit.

The anodic growth of manganese oxide films prepared by potentiostatic and galvanostatic methods has been previously explained in terms of nonhomogeneous deposition or multilayer models. ${ }^{21,22}$ More recently, we have obtained a good fit of the optical data for the galvanostatic growth of $\mathrm{MnO}_{2}$ films in a wide thickness range using a single-film model with optical anisotropy of the oxide. ${ }^{23,24}$ The optical properties obtained for the anisotropic films were found to be dependent on the current density employed for the growth. Figure 2 


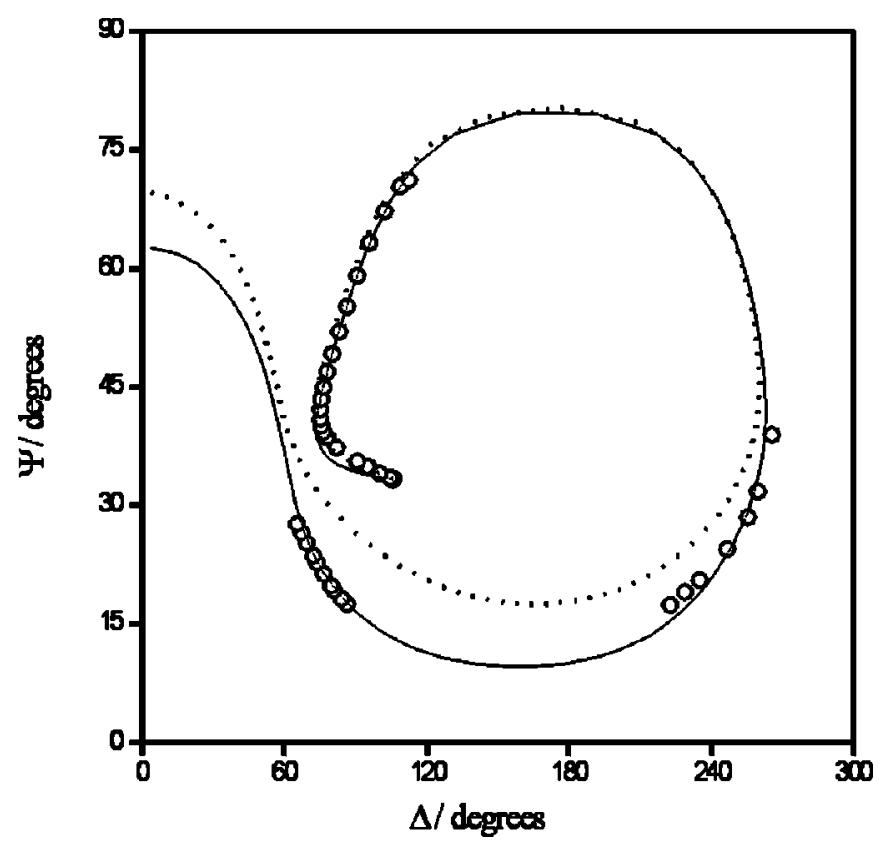

Figure 2. $\Psi-\Delta$ response obtained during $\mathrm{MnO}_{2}$ anodic growth by applying potentiostatic pulses in a $0.1 \mathrm{M} \mathrm{MnSO}_{4}+0.017 \mathrm{M} \mathrm{H}_{2} \mathrm{SO}_{4}$ solution $(\mathrm{pH} 2)$. $E_{\text {in }}=0.65 \mathrm{~V}, E_{\mathrm{f}}=0.75 \mathrm{~V}$. (O) Experimental data. Simulations using $(---)$ the isotropic single-layer model $\left(\mathbf{n}_{f}=1.983-0.083 i\right) ;(\square)$ the anisotropic single-layer model $\left(\mathbf{n}_{\text {ord }}=1.828-0.097 i ; \mathbf{n}_{\mathrm{ex}}=1.964\right.$ $-0.096 i)$.

shows the ellipsometric results for a film grown at $E_{\mathrm{f}}=0.75 \mathrm{~V}$ (in this case $\Psi$ and $\Delta$ values were collected for both signs of ellipticipy) as well as the simulations for the best fit using the single-layer model up to a thickness of $c a .150 \mathrm{~nm}\left(\mathbf{n}_{\mathrm{f}}=1.983-0.083 i\right)$ and using the anisotropic single-film model, which gives values of $\mathbf{n}_{\text {ord }}$ $=1.828-0.097 i$ and $\mathbf{n}_{\text {ex }}=1.964-0.096 i$ for the ordinary and extraordinary complex refractive index of the film, respectively. The optical properties obtained are also dependent on potential. It can be seen from Fig. 2 that deviations of the single-layer are noticeable for thickness values higher than $200 \mathrm{~nm}$.

In summary, although the anodic growth can be adequately described by the anisotropic single-film model with constant index values in the whole thickness range, the differences between the isotropic and anisotropic single layer models are evident for thickness values higher than $c a$. $200 \mathrm{~nm}$ (Fig. 2). Within this restricted thickness range, the anodic film behaves as a single isotropic layer with optical constants that are independent of thickness. Consequently, in the present study of the $\mathrm{MnO}_{2}$ films electroreduction as well as in their response during successive oxidation/reduction cycles in Part II of this series, the simpler isotropic model was chosen for analyzing the optical properties and for calculating the thickness of both the oxidized and electroreduced states for oxide thickness values lower than $c a .150 \mathrm{~nm}$ due to the similar results obtained.

Manganese oxide electroreduction.- $\mathrm{MnO}_{2}$ films of different thickness were obtained according to the procedure described in the Experimental section by applying a different number of potentiostatic pulses. After a given thickness of $\mathrm{MnO}_{2}$ was deposited, the electrode was rinsed, placed in a borate solution, and the electrochemical and ellipsometric measurements were performed according to the procedure described in the Experimental section.

The $\Psi-\Delta$ response for the oxidized and electroreduced films of different thickness is shown in Fig. 3. The oxidized state corresponds to films polarized in the borate electrolyte at $+0.1 \mathrm{~V}$ for 3 min, when the anodic faradaic current rapidly drops to zero. Because

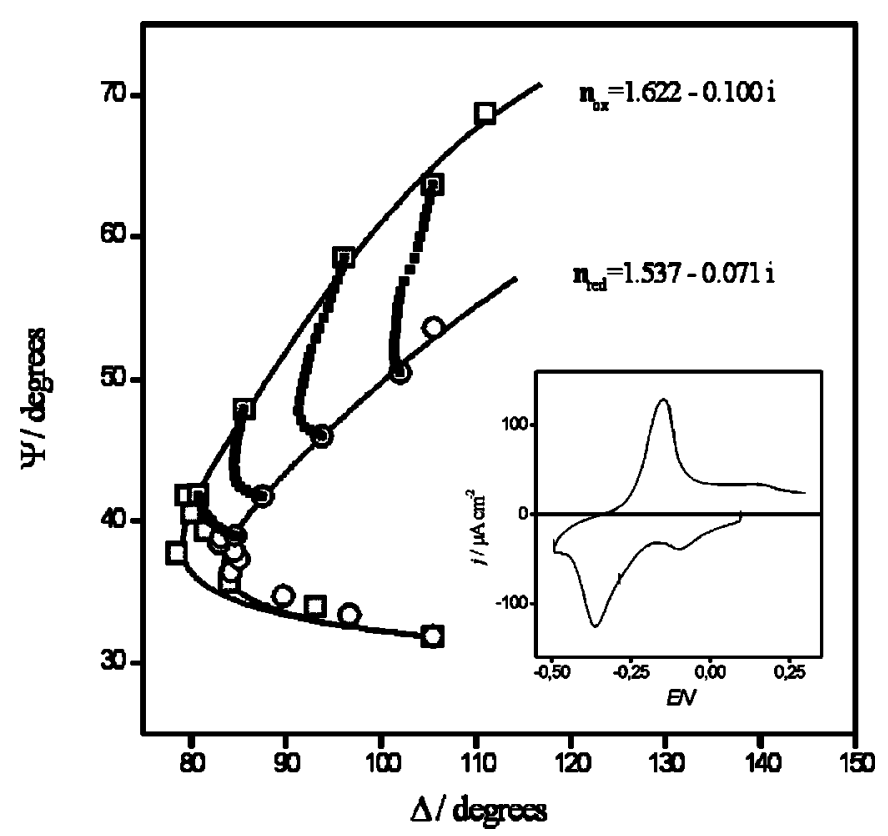

Figure 3. $\Psi-\Delta$ relationship obtained for oxidized $(\square)$ and electroreduced (O) films of different thickness in the borate electrolyte. Solid lines indicate the theoretical lines obtained from fitting with the single-layer model for $\mathbf{n}_{\mathrm{ox}}=1.622-0.100 i$ and $\mathbf{n}_{\mathrm{red}}=1.537-0.071 i$. The data points connecting the oxidized and electroreduced states correspond to the $\Psi-\Delta$ changes obtained during the first electroreduction at $5 \mathrm{mV} \mathrm{s}^{-1}$ for films of different thickness. Inset: potentiodynamic $j / E$ response at $5 \mathrm{mV} \mathrm{s}^{-1}$ of a manganese oxide film of $35 \mathrm{~nm}$ in a $0.1 \mathrm{M}$ borate solution.

the as-prepared samples are a mixture of $\mathrm{Mn}(\mathrm{III})$ and $\mathrm{Mn}(\mathrm{IV})$ species, this treatment was followed with a calculated oxidation state slightly lower than $4 .{ }^{19}$ The content of $\mathrm{Mn}(\mathrm{III})$ present in the electrodeposited $\mathrm{MnO}_{2}$ depends on both the deposition method and the conditions used as well as the water content and $\mathrm{OH}^{-}$ions incorporation into the oxide matrix. ${ }^{32}$ While the potential was held the ellipsometric parameters changed slightly and stabilized after $c a .1$ min. The $\Psi-\Delta$ relationship for the oxidized samples was fitted with the isotropic single-film model up to thickness of $c a .150 \mathrm{~nm}$, which is the same model used during the anodic $\mathrm{MnO}_{2}$ growth in the formation electrolyte. The complex refractive index obtained under these conditions for the oxidized state is $\mathbf{n}_{\mathrm{ox}}=1.622-0.100 i$. The oxide films were electroreduced by scanning the potential from +0.1 to $-0.5 \mathrm{~V}$ at $5 \mathrm{mV} \mathrm{s}^{-1}$ (see inset in Fig. 3). The $\Psi-\Delta$ relationship for electroreduced films of different thickness is also shown in Fig. 3. The best fit using the single-film model leads, in this case, to a value of $\mathbf{n}_{\text {red }}=1.537-0.071 i$, indicating that there is a slight decrease of the refractive index and a more pronounced diminution of the extinction coefficient. Figure 3 also shows the changes in $\Psi$ and $\Delta$ during the first electroreduction cycle at $5 \mathrm{mV} \mathrm{s}^{-1}$ for the films of different thickness.

From the data in Fig. 3 for the oxidized and electroreduced states, the film thickness can also be obtained. The relationship between the film thickness of the oxidized state $\left(d_{\mathrm{ox}}\right)$ and the reduction charge $\left(Q_{\text {red }}\right)$ associated with oxide electroreduction is shown in Fig. 4a. From the slope of the thickness-charge relationship, assuming that the surface roughness is one, and that one electron per manganese oxide [from $\mathrm{Mn}(\mathrm{IV})$ to $\mathrm{Mn}(\mathrm{III})$ ] is transferred, a density value of $1.41 \mathrm{~g} \mathrm{~cm}^{-3}$ is obtained. This low value is comparable with the density obtained by other authors for electrolytic manganese oxide prepared by potentiostatic or galvanostatic methods. ${ }^{21,22}$ However, it should be taken into account that the electroformed manganese oxide film is a nonstoichiometric hydrous oxide, whose composition can be formally described as $\mathrm{MnO}_{x}(\mathrm{OH})_{y}\left(\mathrm{H}_{2} \mathrm{O}\right)_{z}$. Thus, 

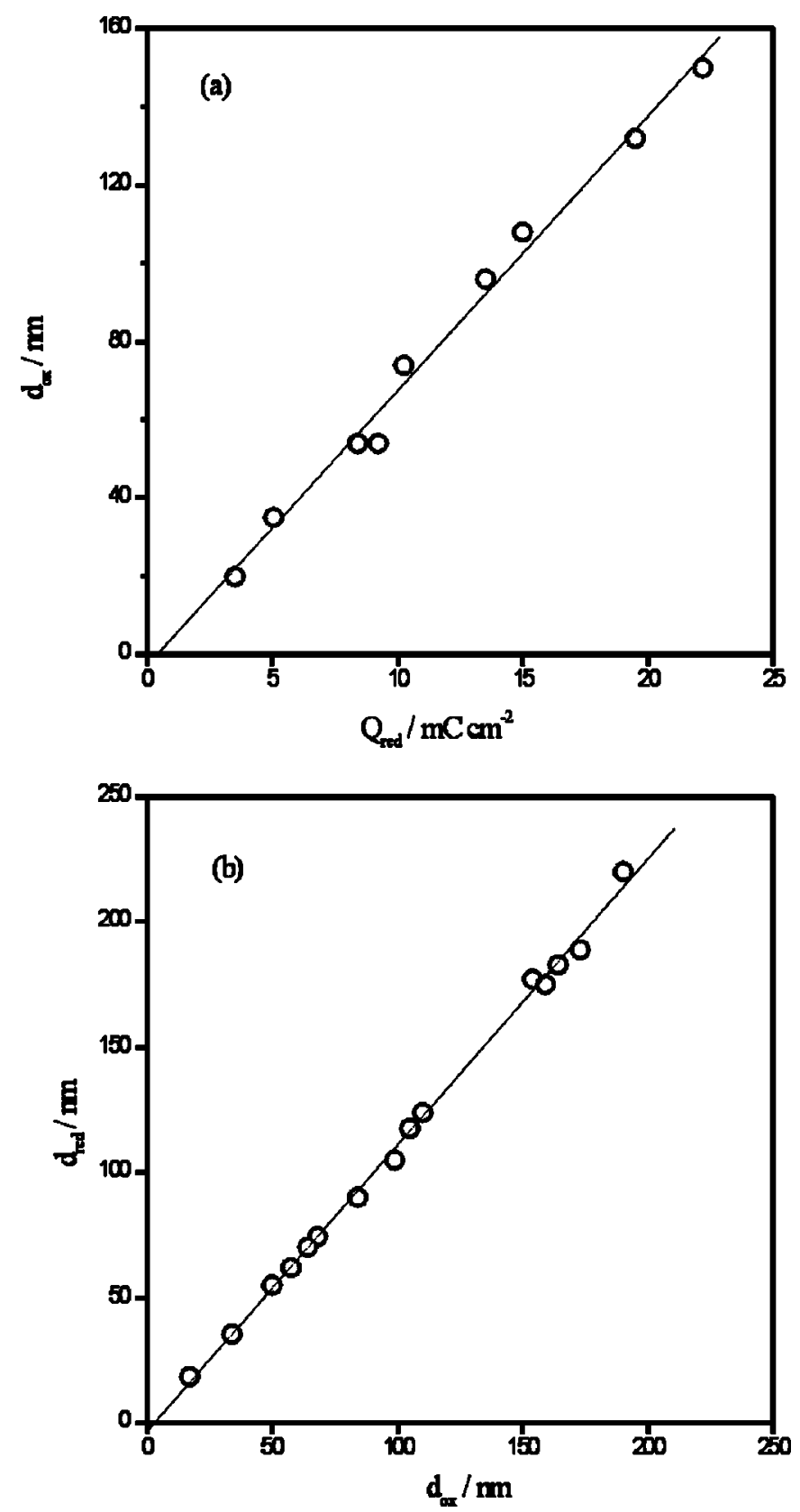

Figure 4. (a) Dependence of the thickness of the oxidized state obtained ellipsometrically with the electroreduction charge; (b) relationship between the thickness for the oxidized and electroreduced states obtained ellipsometrically.

for a manganese oxidation state of +4 , this would correspond to $\mathrm{MnO}_{1.83}(\mathrm{OH})_{0.60}\left(\mathrm{H}_{2} \mathrm{O}\right)_{0.43}$ according to XPS experiments. ${ }^{19}$ Also, an oxidation number of around 3.3 for $\mathrm{Mn}$ after electroreduction in borate solutions has been found. ${ }^{19}$ This value indicates that the oneelectron exchange would not be complete. Accordingly, higher values for the calculated density of manganese oxide would result.

On the other hand, the relationship between the thickness of the oxidized and electroreduced states (Fig. 4b) shows that the electroreduction process is accompanied by an increase in thickness of $c a$. $10 \%$. This value is similar to that found for electroreduction of manganese oxide films prepared by galvanostatic methods. ${ }^{22}$ This lattice expansion has been reported for the reduction of other manganese oxides and has been explained through the octahedral structure distortion due to the formation of $\mathrm{Mn}^{3+}$ species. ${ }^{33}$

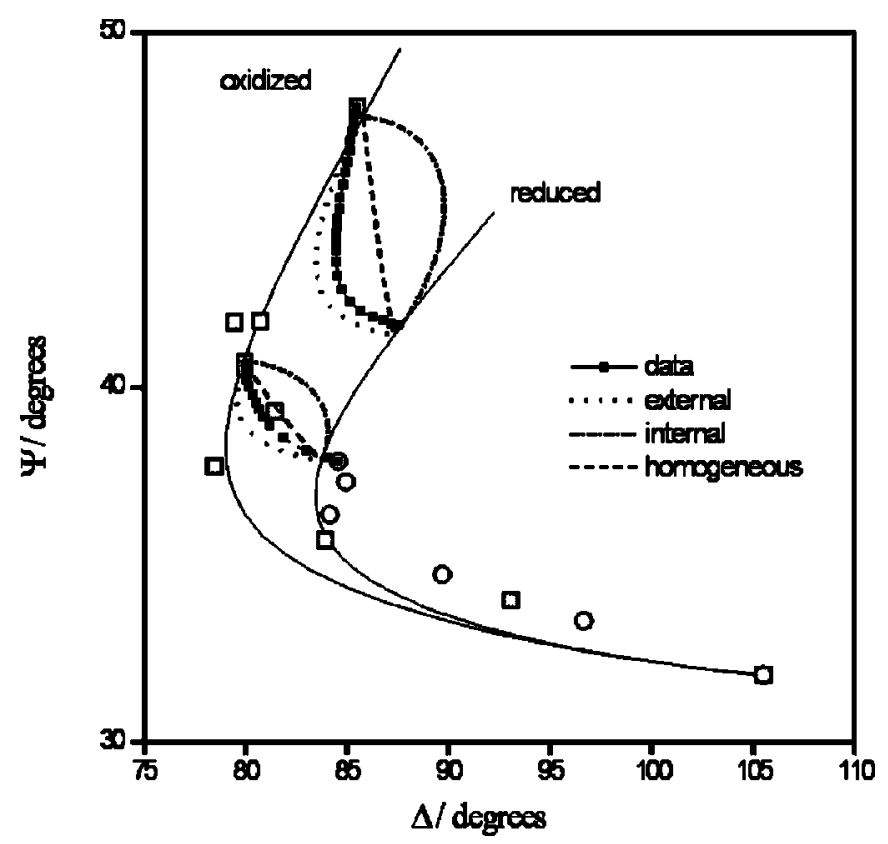

Figure 5. Comparison of experimental data for electroreduction of films of 68 and $84 \mathrm{~nm}$ with simulations for the different conversion models.

Model for Mn(IV)/Mn(III) conversion.-Processes of electrochemical film conversion are, in many cases, associated with significant changes in the optical properties of the film as those shown in Fig. 3 for manganese oxides. Sometimes, the changes in light absorption due to the electrochemical conversion process are reversible and large enough as to make the material appropriate for using in display devices. For these cases, ellipsometry is a powerful tool for analyzing the mode of propagation of the optical changes through the film, as described previously. ${ }^{34}$ The electrochemical conversion process involves injection (or ejection) of electrons and ionic charges in and out of the film. The mechanism of the conversion depends on both the number and the rate of electronic and ionic transfer and transport through the bulk of the film. Theoretical $\Psi-\Delta$ curves for the different mechanisms of film conversion can be simulated if the optical properties of the oxidized and reduced states of the film are known. For a conversion mechanism taking place from the oxide film/electrolyte interface moving inwards, the simulations are made by calculating the change in the ellipsometric parameters for a system consisting of a substrate covered by a dual film in which the thickness of the outer part increases gradually at the expense of the inner part, while for a conversion occurring from the metal/oxide film interface moving outwards, an increase of the inner part is considered (two-layer models). On the other hand, for a mechanism in which the optical properties of the film change continuously during the conversion, a one-layer model with properties changing from one state to the other should be considered. The first case is expected if the ionic charge injection into the film or ionic transport through the film is rate determining in the overall charge injection process, while the second case occurs if the electronic charge is controlling the overall rate. Uniform changes in optical properties are found when electronic and ionic processes within the film show similar rates or when both transport processes are fast. In addition, the thickness variation during the conversion process must be included in the calculations.

Figures 5 and 6 show the $\Psi-\Delta$ data for electroreduction of manganese oxide films of different thickness as compared with those predicted from the different conversion models. The theoretical $\Psi-\Delta$ curves were simulated for conversion of films of different thickness occurring at the oxide/electrolyte interface (external model), the metal/oxide interface (internal model) as well as the uniform change of optical properties (homogeneous model). The optical properties 


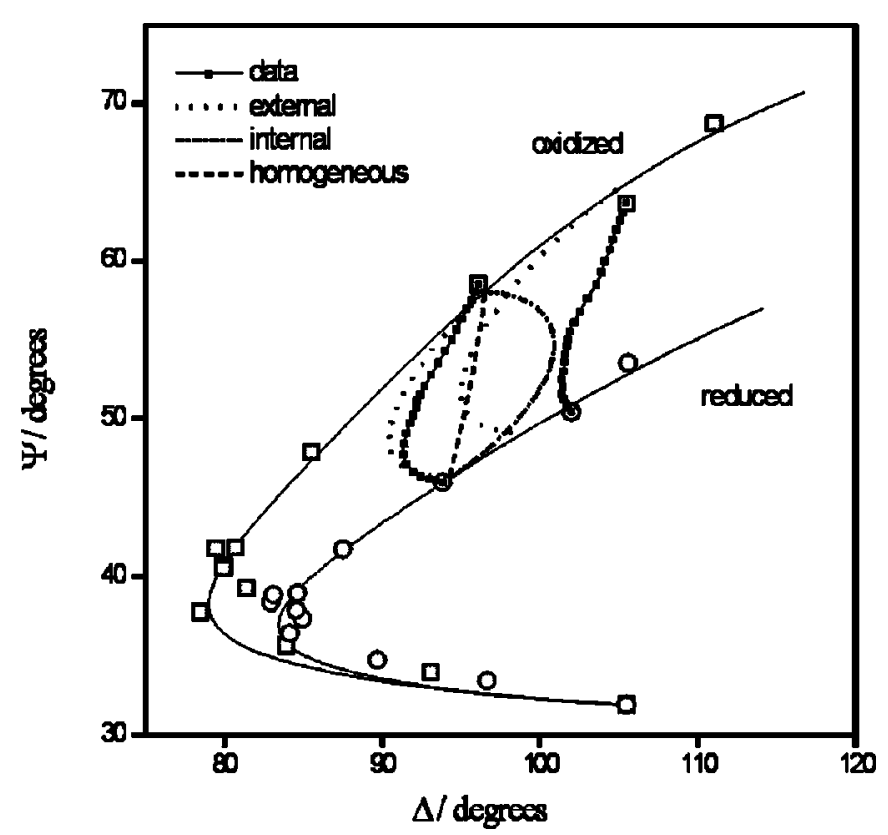

Figure 6. Comparison of experimental data for electroreduction of films of 99 and $110 \mathrm{~nm}$ with simulations for the different conversion models.

of the oxidized and reduced states of manganese oxide obtained from the analysis previously shown in Fig. 3 were employed. Moreover, a $10 \%$ thickness increase on electroreduction (Fig. 4b) has been taken into account in the simulations. For low or intermediate thickness values (up to $c a$. $100 \mathrm{~nm}$ ), the shape of the $\Psi-\Delta$ trace is consistent with a conversion process of manganese oxide to $\mathrm{Mn}$ (III) species in which the thickness of the Mn(III) outer layer increases gradually at the expense of the manganese oxide inner layer (i.e., the external model is taking place), although important deviations are obtained for the film of $110 \mathrm{~nm}$ (Fig. 6). At this point, the reasons for this behavior remain unclear.

In summary, from the discussion of the foregoing ellipsometric results, it can be concluded that the $\mathrm{Mn}$ (IV) to $\mathrm{Mn}$ (III) conversion takes place from the oxide/electrolyte interface inwards. This finding is consistent with results obtained from electrochemical impedance spectroscopy where it is found that for thin manganese oxides, the reduction process is controlled by proton ion diffusion in the bulk oxide. ${ }^{16}$

\section{Conclusions}

The optical response during the anodic growth of manganese oxide films prepared by potentiostatic pulses as well as the $\mathrm{MnO}_{2}$ films electroreduction was determined by in situ ellipsometry. The anodic film growth can be described by a single-film model with optical anisotropy of the oxide, with constant index values in the whole thickness range. Nevertheless, the differences between the isotropic and anisotropic single-layer models are noticeable for thickness values higher than $200 \mathrm{~nm}$. Thin films behave as single isotropic layers with optical properties independent of thickness. The $\Psi-\Delta$ response for the oxidized as well as electroreduced films of different thickness can also be fitted with the isotropic singlelayer model up to thickness values of $c a$. $150 \mathrm{~nm}$. The electroreduction process produces a decrease of the refractive index and the extinction coefficient as well as an increase of $c a .10 \%$ in thickness. The comparison of experimental data with simulated $\Psi-\Delta$ curves for different mechanisms of film conversion indicates that electroreduction of $\mathrm{MnO}_{2}$ to $\mathrm{Mn}(\mathrm{III})$ species is consistent with a gradual increase of the thickness of an outer $\mathrm{Mn}$ (III) oxide layer at the expense of the $\mathrm{MnO}_{2}$ inner layer, i.e., the $\mathrm{Mn}(\mathrm{IV}) \rightarrow \mathrm{Mn}(\mathrm{III})$ conversion takes place from the oxide/electrolyte interface inwards.

\section{Acknowledgments}

Financial support from the Consejo Nacional de Investigaciones Científicas y Técnicas of Argentina (CONICET), the Agencia Córdoba Ciencia S.E., the Agencia Nacional de Promoción Científica y Tecnológica (ANPCyT), the Secretaría de Ciencia y Técnología (SECYT-UNC), and the Consejo de Investigaciones Científicas y Tecnológicas (CICYT-UNSE) is gratefully acknowledged.

\section{References}

1. T. Ohzuku, J. Sato, K. Sawai, and T. Hirai, J. Electrochem. Soc., 138, 2556 (1991)

2. M. J. Duncan, F. Lerouex, J. M. Corbett, and L. F. Nazar, J. Electrochem. Soc., 145, 3746 (1998).

3. C. Cachet-Vivier, S. Bach, and J. P. Pereira-Ramos, Electrochim. Acta, 44, 2705 (1999).

4. G. Pistotis and A. Antonini, J. Electrochem. Soc., 144, 1553 (1997).

5. D. Gosztola and M. Weaver, J. Electroanal. Chem., 271, 141 (1989).

6. K. Kordesch, J. Gsellmann, M. Peri, K. Tomantschger, and R. Chemelli, Electrochim. Acta, 26, 1495 (1981).

7. C. C. Hu and T. W. Tsou, Electrochim. Acta, 47, 3523 (2002).

8. C. C. Hu and C. C. Wang, Electrochim. Acta, 150, A1079 (2003).

9. A. Kozawa and J. Yeager, J. Electrochem. Soc., 112, 959 (1965).

10. A. Kozawa and R. Powers, J. Electrochem. Soc., 115, 1003 (1968).

11. J. M. Amarilla, F. Tedjar, and C. Poinsignon, Electrochim. Acta, 39, 2321 (1994).

12. S. W. Done, G. A. Lawrance, and D. A. Swinkels, J. Electrochem. Soc., 144, 2949 (1997).

13. S. W. Done, G. A. Lawrance, and D. A. Swinkels, J. Electrochem. Soc., 144, 2954 (1997).

14. S. W. Done, G. A. Lawrance, and D. A. Swinkels, J. Electrochem. Soc., 144, 2961 (1997).

15. C. Mondoloni, M. Laborde, J. Rioux, E. Andoni, and C. Lévy-Clément, J. Electrochem. Soc., 139, 954 (1992).

16. L. Gassa, B. A. López de Mishima, and J. R. Vilche, Electrochim. Acta, 42, 1717 (1997).

17. D. Qu, Electrochim. Acta, 48, 1675 (2003)

18. B. A. López de Mishima, T. Ohtsuka, and N. Sato, J. Electroanal. Chem., 243, 219 (1988).

19. B. A. López de Mishima, T. Ohtsuka, K. Konno, and N. Sato, Electrochim. Acta, 36, 1485 (1991).

20. B. A. López de Mishima, T. Ohtsuka, and N. Sato, Electrochim. Acta, 38, 341 (1993)

21. A. Spricis, G. J. Slaidins, J. J. Abele, and J. R. Dzelme, Elektrokhimiya, 18, 301 (1981).

22. J. L. Ord and Z. Q. Huang, J. Electrochem. Soc., 132, 1183 (1985)

23. J. O. Zerbino, A. Maltz, B. A. López de Mishima, M. López Teijelo, and M. Hernández Ubeda, J. Braz. Chem. Soc., 8, 113 (1997).

24. J. O. Zerbino, B. A. López de Mishima, and M. López Teijelo, J. Electroanal. Chem., Submitted.

25. M. Hernández Ubeda, H. Herrera, H. T. Mishima, B. A. López de Mishima, H. M. Villullas, and M. López Teijelo, Electrochim. Acta, 44, 513 (1998).

26. W. H. Press, B. P. Flannery, S. A. Teukolsky, and W. T. Vetterling, Numerical Recipes. The Art of Scientific Computing, Cambridge University Press, Cambridge (1986).

27. D. J. De Smet and J. L. Ord, J. Electrochem. Soc., 136, 2841 (1989).

28. E. M. Patrito and V. A. Macagno, J. Electrochem. Soc., 140, 1576 (1993)

29. E. M. Patrito and V. A. Macagno, J. Electroanal. Chem., 371, 59 (1994).

30. R. M. A. Azzam and N. M. Bashara, Ellipsometry and Polarized Light, North Holland, Amsterdam (1977).

31. Manual for the Automatic 2000FT Ellipsometer (Rudolph Research).

32. N. D. Ivanova, S. A. Kirillov, and A. B. Mishchenko, Electrochim. Acta, 38, 2305 (1993).

33. W. C. Maskell, J. E. A. Shaw, and F. L. Tye, Electrochim. Acta, 26, 1403 (1981).

34. S. Gottesfeld, in Electroanalytical Chemistry, A. J. Bard, Editor, p. 143, Marcel Dekker, New York (1989). 